Revista Universo Contábil, ISSN 1809-3337

Blumenau, v. 10, n. 1, p. 84-103, jan./mar., 2014

doi:10.4270/ruc.2014105

Disponível em www.furb.br/universocontabil

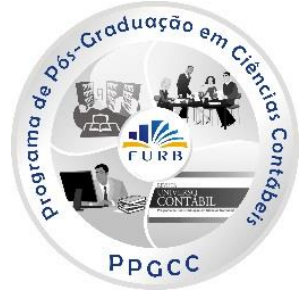

FRAUDES CONTÁBEIS: CARACTERIZAÇÃO E ANÁLISE DAS PUBLICAÇÕES EM PERIÓDICOS E EVENTOS NACIONAIS DE CONTABILIDADE 1

\title{
ACCOUNTING FRAUDS: CHARACTERIZATION AND ANALYSIS OF BRAZILIAN SCIENTIFIC PUBLICATIONS
}

\section{FRAUDES CONTABLES: CARACTERIZACIÓN Y ANÁLISIS DE PUBLICACIONES EN REVISTAS Y EVENTOS DE CONTABILIDAD DE BRASIL}

\author{
Alex Eckert \\ Doutorando em Administração na UCS/PUCRS \\ Professor do Curso de Ciências Contábeis da Universidade de Caxias do Sul \\ Endereço: Rua Francisco Getúlio Vargas, 1130 \\ CEP: 95070-560 - Caxias do Sul - RS \\ E-mail: alex.eckert@bol.com.br \\ Telefone: (54) 3218-2267 \\ Marlei Salete Mecca \\ Doutora em Engenharia da Produção pela UFSC \\ Professora do Curso de Ciências Contábeis da Universidade de Caxias do Sul \\ Endereço: Rua Francisco Getúlio Vargas, 1130 \\ CEP: 95070-560 - Caxias do Sul - RS \\ E-mail: msmecca@gmail.com \\ Telefone: (54) 3218-2267 \\ Roberto Biasio \\ Doutor Administração pela UFRGS \\ Professor do Curso de Ciências Contábeis da Universidade de Caxias do Sul \\ Endereço: Rua Francisco Getúlio Vargas, 1130 \\ CEP: 95070-560 - Caxias do Sul - RS \\ E-mail: rbiasio@commcenter-rs.com.br \\ Telefone: (54) 3218-2267 \\ Graziela Maria Pezzi \\ Bacharel em Ciências Contábeis da Universidade de Caxias do Sul \\ Endereço: Rua Francisco Getúlio Vargas, 1130 \\ CEP: 95070-560 - Caxias do Sul - RS \\ E-mail: grazimpezzi@uol.com.br \\ Telefone: (54) 3218-2267
}

\footnotetext{
${ }^{1}$ Artigo recebido em 21.05.2013. Revisado por pares em 10.10.2013. Reformulado em 06.02.2014. Recomendado para publicação em 27.03.2014 por Carlos Eduardo Facin Lavarda. Publicado em 31.03.2014. Organização responsável pelo periódico: FURB.
} 


\section{RESUMO}

A Contabilidade deve prestar informações fidedignas sobre as entidades, contudo, as frequentes notícias de prática de fraudes acabam gerando incertezas quanto à veracidade das informações apresentadas. O objetivo deste trabalho é verificar como as fraudes contábeis são abordadas nos periódicos e eventos nacionais de Contabilidade no período de 2000 a 2012. Os periódicos e eventos selecionados estão listados no sistema Qualis da CAPES. Para atingir este objetivo, a metodologia de pesquisa adotada foi a descritiva bibliográfica com abordagem quantitativa e qualitativa. A amostra é composta por 25 artigos publicados em periódicos e 11 artigos publicados em eventos nacionais de Contabilidade. Nestes artigos foram identificados os métodos de pesquisa utilizados, os tipos de bibliografia referenciada nos trabalhos, a quantidade de artigos publicados por ano, por estado e instituição representada, bem como o gênero e o número de autores por artigo. A análise dos resultados indica que a implementação de controles internos é uma forma de prevenir a ocorrência de fraudes. Contudo os resultados demonstram que o número de artigos publicados é pequeno se comparado à relevância do tema.

Palavras-chave: Contabilidade. Fraudes. Periódicos. Eventos. Artigos

\section{ABSTRACT}

Accounting should provide reliable information about the organizations, however, the frequent news of fraud have been generating uncertainty about the veracity of the information presented. The aim of this study is to verify how the accounting frauds are addressed in Accounting journals and conferences in the period from 2000 to 2012 in Brazil. The journals and selected events are listed in the system Qualis CAPES. To achieve this goal, the research methodology adopted was the descriptive literature with quantitative and qualitative approach. The sample consists of 25 journal articles and 11 articles published in conferences. In these articles the research methods used and the types of referenced literature were identified. Also, the number of articles published per year, by state and institution represented, the gender and the number of authors per article.The analysis shows that the implementation of internal controls is a way to prevent fraud. However the results show that the number of articles published is small compared to the relevance of the subject.

Keywords: Accounting. Frauds. Journals. Conferences. Articles

\section{RESUMEN}

Contabilidad debe proporcionar información confiable sobre las entidades, sin embargo, la noticiafrecuente de final contra el fraude por generar incertidumbre en cuanto a la veracidad de la información presentada. El objetivo de este trabajo es comprobar cómo se abordan los fraudes contables en revistas y conferencias de contabilidad de Brasil en el período 2000-2012. Periódicos y eventos seleccionados se enumeran en los Qualis CAPES. Para lograr este objetivo, la metodología de investigación utilizada fue la literatura descriptiva, con enfoque cuantitativo y cualitativo. La muestra consta de 25 artículos y 11 artículos publicados en la contabilidad nacional. En estos artículos se identificaron los métodos de investigación utilizados, los tipos de literatura que se hace referencia en el trabajo, el número de artículos publicados por año, según el estado y la institución representada, así como el género y el número de autores por artículo.El análisis de los resultados indica que la aplicación de los controles internos es una manera de prevenir el fraude. Sin embargo, los resultados muestran que el número de artículos publicados es pequeño en comparación con la relevancia del tema.

Palabras clave: Contabilidad. Fraude. Periodicals. Eventos. Artículos. 


\section{INTRODUÇÃO}

A Contabilidade é um instrumento necessário à gestão das empresas, tendo como um de seus principais objetivos a geração de informações que diminuam as incertezas do mercado, facilitando a tomada de decisões. Nas últimas décadas, o ambiente econômico e social tem passado por diversas mudanças que conduziram as empresas em busca de novas formas de gestão. As referidas mudanças podem ocasionar alterações nos processos e procedimentos das organizações, diminuindo os controles internos das mesmas, fato este que possibilita a ocorrência de irregularidades que por vezes culminam na prática de fraudes.

As fraudes podem ser entendidas, de forma ampla, como um processo utilizado para se obter vantagem injusta sobre outra pessoa, seja por ação ou omissão através de conduta culposa ou dolosa. A prática de fraudes pode ocasionar prejuízos para a empresa afetada bem como para fornecedores, investidores e até mesmo para a própria sociedade. Não faltam exemplos de fraudes que culminam em escândalos mundialmente conhecidos, e isto direciona a atenção para os profissionais contábeis envolvidos, especialmente os da área de Auditoria.

Para Ferreira (2010, p.12), tendo em vista a ocorrência de fraudes, muitas vezes os relatórios contábeis acabam perdendo a credibilidade, e estudos relacionados às fraudes já ocorridas podem contribuir para o esclarecimento e resgate da confiança dos usuários.

Dessa forma, o presente trabalho tem o objetivo de analisar como as fraudes contábeis têm sido abordadas, tanto nos periódicos científicos quanto nos eventos nacionais da área, no período de 2000 a 2012. Na visão de Pinheiro e Cunha (2003, p.35) a realização de estudos sobre fraudes, "não tem sido objeto de investigação metodológico-científica na mesma ordem de grandeza que o fenômeno tem sido mensurado em recentes pesquisas através de conceituadas instituições que atuam nos meios empresariais". Os mesmos autores indicam que existem poucos trabalhos sobre fraudes contábeis.

\section{CONTABILIDADE E AUDITORIA}

Coelho e Lins (2010) afirmam que a Contabilidade é uma ciência social que engloba os conhecimentos necessários para o estudo, controle e avaliação do patrimônio de pessoas físicas e jurídicas, nos aspectos quantitativos e qualitativos. Segundo Eckert (2013), a principal finalidade da Contabilidade é subsidiar seus usuários na tomada de decisão.

Conforme Franco (1996, p.22) "a Contabilidade desempenha, em qualquer organismo econômico, o mesmo papel que a História na vida da humanidade". O autor assegura que sem a Contabilidade não se conheceria o passado nem o presente econômico das empresas, além de não ser possível a elaboração de planos orientativos para o futuro.

A história da Contabilidade no Brasil é recente comparando-se a de outros países europeus. Conforme Gelatti e Meneghetti (2010), o primeiro contato da Contabilidade com o Brasil ocorreu devido à necessidade de controle das transações mercantis. Desde então a Contabilidade evoluiu significativamente, tornando-se uma ferramenta indispensável à gestão das empresas.

Para Iudícibus (1997, p.20) a principal função da Contabilidade "permanece inalterada desde seus primórdios", qual seja, a de levar aos usuários das demonstrações financeiras informações que facilitarão a tomada de decisões. Na mesma linha de pensamento, Greco; Arend; Gartner (2009, p.2) sustentam que são finalidades da Contabilidade "assegurar o controle do patrimônio e fornecer as informações sobre a composição e variações patrimoniais, bem como o resultado das atividades econômicas desenvolvidas".

A informação contábil, na visão de Gelatti e Meneghetti (2010, p.71), deve atender aos objetivos que se destina, respeitando padrões de confiabilidade, "fornecendo informações capazes de atender plenamente às necessidades dos usuários".

A necessidade de transparência da informação contábil é defendida por Coelho (2010), ao ponderar que, pelo fato dos mercados onde as empresas atuam estarem se tornando cada dia 
mais complexos e incertos, qualquer decisão tanto de curto quanto de longo prazo deve ser cuidadosamente avaliada quanto aos riscos e oportunidades. Assim, segundo o autor, é importante evidenciar com transparência a todos os interessados na informação contábil não só as últimas decisões tomadas pela empresa e que proporcionaram os resultados atuais, mas também as ações futuras que repercutem no caminho que a empresa vai seguir.

Entretanto, para Menegussi e Ianesko (2008), as informações prestadas pelas entidades, em algumas ocasiões podem estar distorcidas ou não condizentes com a situação da empresa. Para evitar que essa situação ocorra, a Contabilidade dispõe da Auditoria. Nesse sentido, Jund (2007, p.25) afirma que " [...] para mensurar a adequação e confiabilidade dos registros e das demonstrações contábeis, a Contabilidade utiliza-se também de uma técnica que lhe é própria, chamada Auditoria". Esta técnica surge para confirmar "que os controles e as rotinas de trabalho estão sendo habilmente executados e que os dados contábeis, com efetividade, merecem confiança, pois espelham a realidade econômica e financeira da empresa" (ATTIE, 2009, p.4).

\section{FRAUDES CONTÁBEIS}

As fraudes contábeis, segundo entendimento de Iudícibus, Marion e Pereira (2003, p.111) significam "enganar os outros em benefício próprio. Pode ser roubo, desfalque, estelionato, falsificação, etc. Por exemplo, falsificação de documentos, apropriação indevida de bens, cálculos errados". Para Kranacher, Riley e Wells (2010), o ato fraudulento é um erro intencional, seja por ação ou por omissão, fazendo com que sua vítima sofra uma perda econômica ou que seu infrator realize um ganho.

A fraude é um problema comum e crescente nas empresas, "decorrente do enfraquecimento dos valores éticos, morais e sociais e, principalmente, da ineficácia dos sistemas de controle interno" (CREPALDI, 2010, p.377). O autor relata também que a ocorrência dos eventos/condições abaixo elencados, pode representar aumento no risco de fraude ou erro:

- $\quad$ estrutura ou atuação inadequada da administração da entidade auditada ou de algum de seus membros;

- $\quad$ pressões internas e externas;

- $\quad$ transações que pareçam anormais;

- $\quad$ problemas internos no cumprimento dos trabalhos de auditoria;

- fatores específicos no ambiente de sistemas de informação computadorizados;

Nesse sentido, deve-se destacar que existem diferenças entre fraude e erro. Tecnicamente pode-se indicar que o erro é uma ação culposa enquanto a fraude é um ato doloso praticado intencionalmente. As principais diferenças são demonstradas no quadro 1.

Quadro 1: Diferenças entre Erro e Fraude
\begin{tabular}{|l|l|}
\hline \multicolumn{1}{|c|}{ ERRO } & \multicolumn{1}{c|}{ FRAUDE } \\
\hline Ação involuntária & Ação premeditada \\
\hline Esquecimento, desatenção, imperícia & Dolo com intenção \\
\hline Forma estranha à vontade da empresa & Com o intuito de “lavagem de dinheiro" \\
\hline Ato não-intencional & Ato intencional de omissão ou manipulação \\
\hline Omissão & Falsificação ou alteração de registros e documentos \\
\hline Má interpretação de fatos nas demonstrações contábeis & Omissão de transações nos registros contábeis \\
\hline Erros aritméticos & Aplicação de práticas contábeis indevidas \\
\hline Incorreta classificação das contas & Desvios de dinheiro, despesas fictícias \\
\hline Podem levar à falência da empresa & Responsabilidade penal e civil \\
\hline Ocorrem também por falta de conhecimento & Para ocultar desvios ou transações ilegais \\
\hline
\end{tabular}

Fonte: Menegussi e Ianesko (2007,p.13) 
Conforme Pereira e Nascimento (2005), as fraudes e erros praticados contra as organizações ocasionam impactos na sociedade, uma vez que através da globalização da economia, os mercados financeiros passaram a ser mundiais. Sendo assim, as fraudes cometidas por uma empresa estabelecida nos Estados Unidos, por exemplo, terão reflexo nos demais países em que a organização tiver aplicações.

Como resposta aos escândalos envolvendo fraudes contábeis, os Estados Unidos, por exemplo, sancionaram em 2002 a Lei Sarbanes-Oxley (SOX), com o objetivo de restabelecer a confiança pública nas empresas, estabelecendo novos padrões para todas as companhias norteamericanas e também para as empresas estrangeiras que comercializam títulos no mercado daquele país (GELLATTI; MENEGHETTI, 2010).

Dessa forma, conforme Ferreira (2010, p.22), as demandas da SOX "recaem sobre as empresas brasileiras com ações negociadas nos Estados Unidos e sobre as subsidiárias de empresas norte-americanas localizadas no país, pois, normalmente, devem adotar os mesmos controles utilizados pela matriz". Fajardo e Leão (2014) sustentam que, em decorrência da maior inserção do Brasil no contexto global, mesmo as empresas brasileiras tendem cada vez mais a adotar regulamentações exigidas no exterior

A SOX possui por objetivo assegurar a criação de mecanismos de auditoria e segurança confiáveis nas empresas, a fim de evitar a ocorrência de fraudes garantindo clareza para a gestão de empresas (SANTOS; LEMES, 2004). Além das atitudes governamentais, como é o caso da SOX, percebe-se que muitas empresas estão adotando Códigos de Ética, objetivando disseminar conceitos éticos e morais no contexto organizacional. Entretanto, isso não tem sido capaz de gerar atitudes éticas nas organizações, o que as leva a utilizar outros mecanismos para reforçar este comportamento. (SELVARAJAN; CLONINGER, 2008)

\section{PROCEDIMENTOS METODOLÓGICOS}

Quanto aos procedimentos técnicos, este estudo é classificado como uma pesquisa bibliográfica. As pesquisas bibliográficas tentam explicar um problema utilizando o conhecimento disponível a partir das teorias publicadas e a partir de material já elaborado, principalmente livros e artigos científicos. (GIL, 1999; KÖCHE, 2010)

Em relação aos objetivos, a pesquisa a ser realizada é descritiva, uma vez pretende verificar como as fraudes contábeis são abordadas nos periódicos e eventos nacionais de Contabilidade no período de 2000 a 2012. Cervo e Bervian (2002, p.66) consideram que "a pesquisa descritiva observa, registra, analisa e correlaciona fatos ou fenômenos (variáveis) sem manipulá-los". Na mesma linha de pensamento, Furasté (2006) indica que na pesquisa descritiva são identificados, classificados e analisados fatos sem qualquer interferência do pesquisador.

Quanto à forma de abordagem do problema, a presente pesquisa tem características qualitativas e quantitativas. Richardson (1999) indica que as pesquisas qualitativas podem descrever a complexidade de determinado problema, analisar a interação de certas variáveis, compreender e classificar processos dinâmicos vividos por grupos sociais.

A pesquisa também pode ser classificada como quantitativa, uma vez que a estatística descritiva será utilizada para quantificar o número de artigos sobre fraudes contábeis publicados. Nesse sentido, Richardson (1999, p.70) afirma que a abordagem quantitativa "caracteriza-se pelo emprego de quantificação tanto nas modalidades de coleta de informações, quanto no tratamento delas por meio de técnicas estatísticas”.

\section{CARACTERIZAÇÃO DAS PUBLICAÇŌES}

A obtenção da amostra ocorreu na população referente aos artigos publicados em periódicos e eventos nacionais de Contabilidade no período de 2000 a 2012. Dessa forma a 
obtenção da amostra para o desenvolvimento da pesquisa foi dividida em duas etapas, que serão demonstradas a seguir.

A primeira parte da amostra foi obtida através de uma triagem dos artigos publicados em periódicos nacionais que tratem de Contabilidade, publicados entre os anos 2000 e 2012. Para tanto, localizou-se, no endereço eletrônico da CAPES (qualis.capes.gov.br) a lista completa de periódicos classificados no Qualis na grande área "Administração, Contabilidade e Turismo".

Essa triagem inicial identificou 1.503 periódicos, dos quais, filtraram-se somente aqueles classificados entre A1 e B5, que possuíam o termo "Contabilidade" ou "Contábil" em seu título, redigidos em português e disponibilizados gratuitamente na internet. Dessa forma, foram selecionados 19 periódicos indicados no quadro 2.

Quadro 2: Periódicos da amostra

\begin{tabular}{|l|l|l|c|}
\hline No & ISSN & Titulo & Estrato \\
\hline PE01 & $1808-057 X$ & Revista Contabilidade \& Finanças (Online) & A2 \\
\hline PE02 & $0103-734 X$ & Contabilidade Vista \& Revista & B1 \\
\hline PE03 & $1982-6486$ & Revista de Contabilidade e Organizações & B1 \\
\hline PE04 & $1809-3337$ & Revista Universo Contábil & B1 \\
\hline PE05 & $1984-3925$ & Contabilidade, Gestão e Governança & B2 \\
\hline PE06 & $1519-0412$ & Pensar Contábil & B3 \\
\hline PE07 & $2178-7638$ & RACEF - Revista de Administração, Contabilidade e Economia da FUNDACE & B3 \\
\hline PE08 & $1984-6266$ & RC\&C. Revista de Contabilidade e Controladoria & B3 \\
\hline PE09 & $2179-734 X$ & Registro Contábil - RECONT & B3 \\
\hline PE10 & $2176-9036$ & Revista Ambiente Contábil & B3 \\
\hline PE11 & $1807-1821$ & Revista Contemporânea de Contabilidade (UFSC) & B3 \\
\hline PE12 & $1981-8610$ & Revista de Educação e Pesquisa em Contabilidade & B3 \\
\hline PE13 & $1982-3967$ & Revista de Informação Contábil (UFPE) & B3 \\
\hline PE14 & $1982-7342$ & Sociedade, Contabilidade e Gestão (UFRJ) & B3 \\
\hline PE15 & $1678-6483$ & RACE : Revista de Administração, Contabilidade e Economia & B4 \\
\hline PE16 & $1808-3781$ & Revista Catarinense da Ciência Contábil & B4 \\
\hline PE17 & $1984-3704$ & Revista de Contabilidade da UFBA & B4 \\
\hline PE18 & $1984-3291$ & Revista de Contabilidade do Mestrado em Ciências Contábeis da UERJ (Online) & B4 \\
\hline PE19 $2177-8426$ & Revista de Administração e Contabilidade da FAT & B5 \\
\hline
\end{tabular}

Fonte: elaborado pelos autores

Após a seleção, realizou-se o acesso ao site de cada um dos 19 periódicos indicados no Quadro 3, buscando os artigos que contemplassem a palavra "fraudes" no título, no resumo ou nas palavras-chaves. Essa busca localizou 28 artigos que atenderam os requisitos da pesquisa, dos quais se efetuou o download.

Em seguida, realizou-se uma segunda triagem na amostra, pois se observou que haviam dois artigos idênticos publicados em periódicos e períodos diferentes. Dessa forma considerouse apenas a primeira publicação de cada um deles, resultando na amostra de 26 publicações, identificadas no quadro 3.

A segunda parte da amostra foi obtida em eventos nacionais da área contábil. A seleção foi realizada com base na lista de eventos qualificados pela CAPES em 2009. Entre os 106 eventos listados, foram filtrados aqueles realizados no Brasil, e que possuíam o termo "contabilidade" ou "contábil" em seu título. Assim, foram identificados 03 eventos, os quais estão relacionados no quadro 4.

A seleção das publicações em eventos de Contabilidade ocorreu através da busca automática do termo "fraudes" no artigo. O Congresso ANPCONT (EV01) ocorre desde 2006, portanto não há artigos publicados entre 2000 a 2005. Já entre 2006 e 2012, que é o período pesquisado, foi localizado 1 artigo. 


\begin{tabular}{|c|c|c|c|c|}
\hline PERIÓDIC & ANO & IDENTIFICAÇÃO & ARTIGO & REFERÊNCIA \\
\hline \multirow{4}{*}{ P01 } & 2002 & ART01 & $\begin{array}{l}\text { A auditoria legal na União Europeia: enquadramento, debate atual e } \\
\text { perspectivas futuras }\end{array}$ & (ALMEIDA, 2002) \\
\hline & 2004 & ART02 & Auditoria e sociedade: o diálogo necessário & (ALMEIDA, 2004) \\
\hline & 2007 & ART03 & $\begin{array}{l}\text { Rodízio de firmas de auditoria: a experiência brasileira e as conclusões do } \\
\text { mercado }\end{array}$ & (OLIVEIRA; SANTOS, 2007) \\
\hline & 2009 & ART04 & $\begin{array}{l}\text { Aplicações da lei de Newcomb-Benford na auditoria tributária do imposto } \\
\text { sobre serviços de qualquer natureza (ISS) }\end{array}$ & (SANTOS et.al, 2009) \\
\hline \multirow{4}{*}{ P02 } & 2003 & ART05 & A Importância da Auditoria na detecção de fraudes & (PINHEIRO; CUNHA, 2003) \\
\hline & 2004 & ART06 & $\begin{array}{l}\text { Controles internos empresariais e gestão: visões e importância - uma } \\
\text { abordagem exploratória }\end{array}$ & (PEREIRA, 2004) \\
\hline & 2007 & ART07 & $\begin{array}{l}\text { Governança Corporativa e remuneração de executivos: uma revisão de } \\
\text { artigos publicados no exterior }\end{array}$ & (SOUZA; BORBA, 2007) \\
\hline & 2009 & ART08 & $\begin{array}{l}\text { Comitê de auditoria ou órgãos equivalentes no contexto da Lei Sarbanes- } \\
\text { Oxley: estudo da percepção dos gestores de empresas brasileiras } \\
\text { emitentes de American Depositary Receipts - ADRs }\end{array}$ & $\begin{array}{l}\text { (PELEIAS; SEGRETI; } \\
\text { COSTA, 2009) }\end{array}$ \\
\hline P03 & 2007 & ART09 & $\begin{array}{l}\text { Aplicação de métodos quantitativos em auditoria: propostas para otimizar } \\
\text { procedimentos e reduzir riscos }\end{array}$ & (RIBEIRO; DIAS FILHO, 2007) \\
\hline P04 & 2008 & ART10 & $\begin{array}{l}\text { Relevância dos red flags na avaliação do risco de fraudes nas } \\
\text { demonstrações contábeis: a percepção de auditores independentes } \\
\text { hrasileirns }\end{array}$ & $\begin{array}{l}\text { (MURCIA;BORBA;SCHIEHLL, } \\
\text { 2008) }\end{array}$ \\
\hline P05 & 2010 & ART11 & $\begin{array}{l}\text { Custo-benefício do controle: proposta de um método para avaliação com } \\
\text { base no COSO }\end{array}$ & (DANTAS et.al, 2010) \\
\hline \multirow{2}{*}{ P06 } & 2007 & ART12 & $\begin{array}{l}\text { A evidenciação da informação contábil com relação à tributação no } \\
\text { comércio eletrônico: um estudo de caso }\end{array}$ & $\begin{array}{l}\text { (JUVENAL; CAMPAGNAC, } \\
\text { 2007) }\end{array}$ \\
\hline & 2008 & ART13 & $\begin{array}{l}\text { Uma contribuição à análise de fatores que influenciam o equilibrio do } \\
\text { sistema previdenciário }\end{array}$ & $\begin{array}{l}\text { (FÉLIX; RIBEIRO; TOSTES, } \\
\text { 2008) }\end{array}$ \\
\hline P11 & 2007 & ART14 & $\begin{array}{l}\text { Políticas de segurança em sistemas de informação contábil: um estudo em } \\
\text { cooperativas de crédito do estado de Minas Gerais }\end{array}$ & (ANDRADE et.al, 2007) \\
\hline \multirow{3}{*}{ P12 } & 2011 & ART15 & $\begin{array}{l}\text { A percepção sobre ética de estudantes de curso de graduação em } \\
\text { Ciências Contábeis }\end{array}$ & $\begin{array}{l}\text { (FREITAS; DIEHL; } \\
\text { MACAGNAN, 2011) }\end{array}$ \\
\hline & 2011 & ART16 & $\begin{array}{l}\text { SPED - Sistema Público de Escrituração Digital: Percepção dos } \\
\text { contribuintes em relação aos impactos de sua adoção }\end{array}$ & (GERON et.al, 2011) \\
\hline & 2012 & ART17 & Ética profissional contábil: uma análise visual da percepção pública & $\begin{array}{l}\text { (AZEVEDO; } \\
\text { CORNACCHIONE JUNIOR, } \\
\text { 2012) }\end{array}$ \\
\hline $\mathrm{P} 13$ & 2010 & ART18 & $\begin{array}{l}\text { Uma visão atual do processo de controle e gerenciamento de riscos } \\
\text { operacionais nos maiores bancos brasileiros }\end{array}$ & $\begin{array}{l}\text { (FERNANDES; } \\
\text { KROENRE;SOTHE, 2010) }\end{array}$ \\
\hline \multirow{3}{*}{ P16 } & 2006 & ART19 & $\begin{array}{l}\text { O uso do controle interno na gestão das operações: um estudo de caso em } \\
\text { empresa hoteleira }\end{array}$ & (LUNKES; ROSA, 2006) \\
\hline & 2010 & ART20 & $\begin{array}{l}\text { Análise comparativa do controle interno no contas a receber e a pagar nas } \\
\text { empresas Beta Ltda e Alfa Ltda }\end{array}$ & (RITA, 2010) \\
\hline & 2002 & ART21 & Perspectivas da profissão contábil & (SANTOS, 2002) \\
\hline \multirow{5}{*}{ P18 } & 2005 & ART22 & $\begin{array}{l}\text { Um estudo das fraudes contábeis sob duas óticas: jornais econômicos } \\
\text { versus periódicos acadêmicos no período de 2001-2004 }\end{array}$ & (MURCIA; BORBA, 2005) \\
\hline & 2005 & ART23 & Governança corporativa: solução, paliativo ou modismo & (CARDOZO, 2005) \\
\hline & 2007 & ART24 & Fraudes eletrônicas: O que há de novo? & (BASTOS; PEREIRA, 2007) \\
\hline & 2007 & ART25 & $\begin{array}{l}\text { Atuação dos contadores e auditores na descoberta e na apuração de } \\
\text { fraudes: uma reflexão }\end{array}$ & $($ SILVA, 2007) \\
\hline & 2012 & ART26 & $\begin{array}{l}\text { Teoria dos escândalos corporativos: uma análise comparativa de casos } \\
\text { brasileiros e norteamericanos }\end{array}$ & $\begin{array}{l}\text { (COUTINHO E SILVA et. al, } \\
\text { 2012) }\end{array}$ \\
\hline
\end{tabular}

Fonte: elaborado pelos autores

Quadro 4: Eventos da amostra

\begin{tabular}{|l|l|l|}
\hline No & \multicolumn{1}{|c|}{ EVENTO } & ESTRATO \\
\hline EV01 & ANPCONT - Congresso ANPCONT & E1 \\
\hline EV02 & CCC- USP - Congresso USP de Controladoria e Contabilidade & E1 \\
\hline EV03 & EnPEQ - Encontro de Ensino e Pesquisa em Administração e Contabilidade & E1 \\
\hline
\end{tabular}

Fonte: elaborado pelos autores 
A base para a seleção da amostra no Congresso USP de Controladoria e Contabilidade (EV02) foram as 11 edições, realizadas no período de 2000 a 2012. Foram encontrados 10 artigos que atendiam os requisitos da pesquisa. O EnPEQ (EV03) não teve nenhum artigo apresentado que contemplasse o termo pesquisado. Dessa forma chegou-se ao número de 11 artigos, que estão demonstrados no quadro 5.

\begin{tabular}{|c|c|c|c|c|}
\hline EVENTO & ANO & IDENTIFICAÇÃO & ARTIGO & REFERÊNCIA \\
\hline EV01 & 2012 & ART27 & $\begin{array}{l}\text { Viagem ao centro da denúncia: explorando as "camadas" que } \\
\text { influenciam as denúncias de fraudes nas organizações, na } \\
\text { perspectiva dos contabilistas }\end{array}$ & (FAJARDO; CARDOSO, 2012) \\
\hline \multirow{10}{*}{ EV02 } & 2004 & ART28 & $\begin{array}{l}\text { A Lei Sarbanes-Oxley: uma tentativa de recuperar a credibilidade do } \\
\text { mercado de capitais norte-americano }\end{array}$ & (SANTOS; LEMES, 2004) \\
\hline & 2004 & ART29 & $\begin{array}{l}\text { A importância da Auditoria e Perícia para o combate a fraudes e } \\
\text { erros na Contabilidade das empresas }\end{array}$ & (MEDEIROS; SÉRGIO; BOTELHO, 2004 \\
\hline & 2005 & ART30 & Earnings Management no contexto bancário brasileiro & (FUJl; CARVALHO, 2005) \\
\hline & 2007 & ART31 & $\begin{array}{l}\text { A influência da Lei Sarbanex-Oxley e do Código Civil Brasileiro nos } \\
\text { controles internos de empresas localizadas no Brasil }\end{array}$ & (SILVA; NASCIMENTO; OTT, 2007) \\
\hline & 2007 & ART32 & Gerenciamento de Resultados Contábeis: causas e consequências & (MATSUMOTO; PARREIRA, 2007) \\
\hline & 2007 & ART33 & $\begin{array}{l}\text { Relevância dos Red Flags na Avaliação do Risco de Fraudes nas } \\
\text { Demonstrações Contábeis: A Percepção de Auditores } \\
\text { Independentes Brasileiros }\end{array}$ & (MURCIA; BORBA; SCHIEHLL, 2007) \\
\hline & 2008 & ART34 & $\begin{array}{l}\text { O impacto da Lei Sarbanes-Oxley (SOX) no conservadorismo } \\
\text { contábil das empresas brasileiras que emitiram ADR antes de } \\
\text { 2002: uma investigação utilizando dados em painel }\end{array}$ & (MENDONÇA, et.al, 2008) \\
\hline & 2010 & ART35 & $\begin{array}{l}\text { Análise digital: uma abordagem cognitiva na detecção de não } \\
\text { conformidade em prestações de contas municipais }\end{array}$ & (DINIZ; CORRAR; SLOMSKI, 2010) \\
\hline & 2011 & ART36 & $\begin{array}{l}\text { O papel do controle interno na prevenção de erros e fraudes: um } \\
\text { estudo de caso em cooperativa de crédito de Minas Gerais }\end{array}$ & (OLIVEIRA, et.al, 2011) \\
\hline & 2012 & ART37 & Impactos da adoção dos IFRSs na perícia criminal & (SOUZA; CARDOSO, 2012) \\
\hline
\end{tabular}

Fonte: elaborado pelos autores

Assim, foram selecionados 26 artigos publicados em periódicos nacionais de Contabilidade e 11 artigos publicados em eventos nacionais de Contabilidade. Contudo, verificou-se que o artigo "Relevância dos red flags na avaliação do risco de fraudes nas demonstrações contábeis: a percepção de auditores independentes brasileiros" foi apresentado no EV02 (ART33) e publicado no ano seguinte no PE04 (ART10). Dessa forma, o ART10 será excluído da amostra dos periódicos, ou seja, será considerado apenas o ART33 para fins de análise, resultando na amostra final de acordo com o quadro 6.

Quadro 6: Amostra final utilizada

\begin{tabular}{|l|c|}
\hline & QUANTIDADE ARTIGOS \\
\hline PERIÓDICOS & 25 \\
\hline EVENTOS & 11 \\
\hline TOTAL & $\mathbf{3 6}$ \\
\hline
\end{tabular}

Fonte: elaborado pelos autores

Os artigos selecionados foram analisados sob a abordagem quantitativa e qualitativa. Para tanto, foi efetuada a leitura e análise, especialmente do resumo, introdução, metodologia e conclusão de cada artigo. Inicialmente, efetuou-se o levantamento dos artigos publicados nos periódicos e eventos selecionados, no período de 2000 a 2012. A tabela 1 apresenta, ano a ano, a quantidade de artigos publicados sobre fraudes.

Verifica-se que o maior número de artigos publicados referente a fraudes ocorreu no ano de 2007, uma vez que nesse ano houve a publicação de $28 \%$ dos artigos localizados, seguido dos anos 2004, 2010 e 2012 com 11\% das publicações em cada ano. Não foram localizadas publicações nos anos de 2000 e 2001.

A contabilização dos artigos por estado e instituição, para os casos de publicações com autores com filiações acadêmicas diversas, considerou o conceito utilizado por Cardoso, Pereira 
e Guerreiro (2007), ou seja, considerou-se a origem (instituição) vinculada ao primeiro autor. Dessa forma, a distribuição dos artigos por instituição e estado é apresentada na tabela 2.

Tabela 1 - Artigos publicados por ano

\begin{tabular}{ccc} 
Ano & Artigos publicados & Percentual \\
\hline 2000 & 0 & $0 \%$ \\
2001 & 0 & $0 \%$ \\
2002 & 2 & $6 \%$ \\
2003 & 1 & $3 \%$ \\
2004 & 4 & $11 \%$ \\
2005 & 3 & $8 \%$ \\
2006 & 1 & $3 \%$ \\
2007 & 10 & $28 \%$ \\
2008 & 2 & $6 \%$ \\
2009 & 2 & $6 \%$ \\
2010 & 4 & $11 \%$ \\
2011 & 3 & $8 \%$ \\
2012 & 4 & $11 \%$ \\
\hline Total & 36 & $100 \%$ \\
\hline
\end{tabular}

Fonte: elaborado pelos autores

Tabela 2 - Artigos publicados por instituição representada e estado

\begin{tabular}{|c|c|c|c|}
\hline Instituição/Estado & $\mathrm{N}^{\circ}$ de artigos & Percentual por instituição & $\begin{array}{c}\text { Percentual por } \\
\text { estado }\end{array}$ \\
\hline UFBA/BA & 1 & $3 \%$ & $3 \%$ \\
\hline $\mathrm{UCB} / \mathrm{DF}$ & 1 & $3 \%$ & \multirow{2}{*}{$6 \%$} \\
\hline $\mathrm{UnB} / \mathrm{DF}$ & 1 & $3 \%$ & \\
\hline FCHV/ES & 1 & $3 \%$ & \multirow{2}{*}{$6 \%$} \\
\hline FUCAPE/ES & 1 & $3 \%$ & \\
\hline UFMG/MG & 1 & $3 \%$ & \multirow{3}{*}{$8 \%$} \\
\hline UFU/MG & 1 & $3 \%$ & \\
\hline UFVJM/MG & 1 & $3 \%$ & \\
\hline UFP/PE & 1 & $3 \%$ & $3 \%$ \\
\hline UERJ/RJ & 5 & $14 \%$ & \multirow{3}{*}{$22 \%$} \\
\hline UFF/RJ & 1 & $3 \%$ & \\
\hline FGV/RJ & 2 & $6 \%$ & \\
\hline UFRGN/RN & 1 & $3 \%$ & $3 \%$ \\
\hline UNISINOS/RS & 2 & $6 \%$ & $6 \%$ \\
\hline FURB/SC & 1 & $3 \%$ & \multirow{3}{*}{$19 \%$} \\
\hline UFSC/SC & 5 & $14 \%$ & \\
\hline UNESC/SC & 1 & $3 \%$ & \\
\hline Faculdade São Luiz/SP & 1 & $3 \%$ & \multirow{3}{*}{$17 \%$} \\
\hline FECAP/SP & 1 & $3 \%$ & \\
\hline USP/SP & 4 & $11 \%$ & \\
\hline Outras Instituições & 3 & $8 \%$ & $8 \%$ \\
\hline Total & 36 & $100 \%$ & $100 \%$ \\
\hline
\end{tabular}

Fonte: elaborado pelos autores 
Os resultados indicam que a UERJ e a UFSC são as instituições com maior representatividade, apresentando cinco artigos cada no período analisado. Em terceiro lugar aparece a USP com a publicação de quatro artigos. Na tabela 2, foram registrados em "outras instituições" os dois artigos (ART01 e ART02) elaborados por instituições de ensino portuguesas e o ART06, no qual não estava informada a instituição atrelada.

Ainda na tabela 2, pode-se constatar que o estado com maior representatividade é o RJ com $22 \%$ do total dos artigos publicados, seguido de SC com $19 \%$ e SP com $17 \%$ das publicações. Dessa forma, verifica-se que o tema em estudo é disseminado em todo país, uma vez que a maioria das regiões apresenta a publicação ao menos de um artigo.

Em se tratando do gênero dos autores, $75 \%$ dos autores dos artigos selecionados são do gênero masculino, conforme figura 1.

Figura 1 - Gênero dos autores

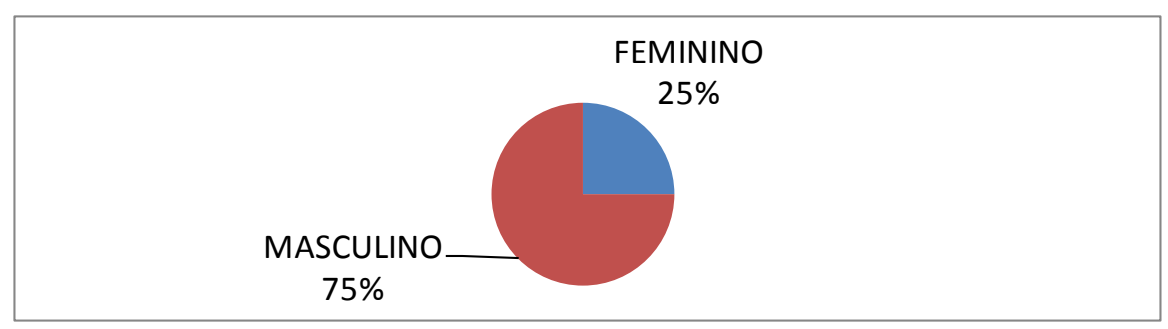

Fonte: elaborado pelos autores

Observou-se que a elaboração dos artigos geralmente ocorre em forma de parceria, uma vez que predominam os trabalhos desenvolvidos entre discentes e docentes. Tal observação é comprovada pelos dados da Tabela 3, uma vez que $42 \%$ dos trabalhos foram desenvolvidos por dois autores, $22 \%$ por três autores, enquanto apenas $19 \%$ dos artigos foram desenvolvidos por autoria individual. A tabela 3 , apresentada a seguir, indica o número de autores por artigo.

Tabela 3 - Número de autores por artigo

\begin{tabular}{ccc}
\hline $\mathrm{N}^{\mathrm{o}}$ de autores & Artigos & Percentual \\
\hline 1 & 7 & $19 \%$ \\
2 & 15 & $42 \%$ \\
3 & 8 & $22 \%$ \\
4 & 5 & $14 \%$ \\
5 & 1 & $3 \%$ \\
\hline Total & 36 & $100 \%$ \\
\hline
\end{tabular}

Fonte: elaborado pelos autores

Para efetuar o levantamento da evolução das referências bibliográficas indicadas nos artigos utilizou-se disposição proposta por Beuren, Schlindwein e Pasqual (2007), na qual as bibliografias são segregadas em: livros; periódicos; teses e dissertações; normas; jornais; sites da web e outros. Dessa forma os resultados encontrados são os dispostos na tabela 4.

O número médio de referências indicadas em cada artigo é 22 , considerando-se a amostra de 36 artigos e o número total de 805 referências indicadas nos trabalhos. Entre as 805 referências bibliográficas citadas, ressalta-se que 35\% são representadas por livros e $31 \%$ por periódicos.

O resultado demonstra que a abordagem dos artigos selecionados é conservadora, uma vez que os livros demoram mais tempo para atualizar as informações. Contudo pode-se verificar que em 2012 o número de periódicos referenciados foi expressivo, indicando que os artigos 
recentes estão acompanhando o avanço da ciência. Esse dado é corroborado pelo fato de Sites Web estarem em terceiro lugar com $14 \%$ das referências.

Tabela 4 - Evolução dos tipos de referências bibliográficas

\begin{tabular}{|c|c|c|c|c|c|c|c|c|c|c|c|c|c|}
\hline Tipo de bibliografia & 200020012002 & 2003 & 2004 & 2005 & 2006 & 2007 & 2008 & 2009 & 2010 & 2011 & 2012 & Total & Percentual \\
\hline Livros & 8 & 5 & 40 & 8 & 7 & 66 & 8 & 38 & 42 & 33 & 25 & 280 & $35 \%$ \\
\hline Periódicos & 1 & 2 & 22 & 35 & & 29 & 8 & 20 & 34 & 10 & 86 & 247 & $31 \%$ \\
\hline Teses e dissertações & & & & 1 & & 4 & 2 & 2 & 6 & 4 & 3 & 22 & $3 \%$ \\
\hline Normas & & 1 & 4 & 1 & & 12 & 4 & 3 & 1 & 7 & 3 & 36 & $4 \%$ \\
\hline Jornais & 1 & 2 & 1 & 12 & & 1 & & & & & 1 & 18 & $2 \%$ \\
\hline Sites Web & 1 & 6 & 20 & 4 & 1 & 28 & 10 & 9 & 9 & 16 & 6 & 110 & $14 \%$ \\
\hline Outros & & & 6 & 11 & & 19 & 6 & & 19 & 10 & 21 & 92 & $11 \%$ \\
\hline Total & 11 & 16 & 93 & 72 & 8 & 159 & 38 & 72 & 111 & 80 & 145 & 805 & $100 \%$ \\
\hline Média por artigo & 6 & 16 & 23 & 14 & 8 & 16 & 19 & 36 & 28 & 27 & 36 & 22 & \\
\hline
\end{tabular}

Fonte: elaborado pelos autores

Em contrapartida, observa-se que os tipos de referências bibliográficas com menor participação são normas com $4 \%$, teses e dissertações com $3 \%$ e jornais, com $2 \%$ do total utilizado.

A figura 2 indica os procedimentos de pesquisa utilizados para a elaboração dos 36 artigos selecionados. Observa-se que a maior parte dos artigos (36\%), foram elaborados através da utilização de pesquisa bibliográfica, $31 \%$ dos artigos foram desenvolvidos com base em pesquisa survey, $22 \%$ em estudo de caso e apenas $11 \%$ das publicações utilizaram a pesquisa documental como procedimento.

Figura 2 - Procedimento de pesquisa

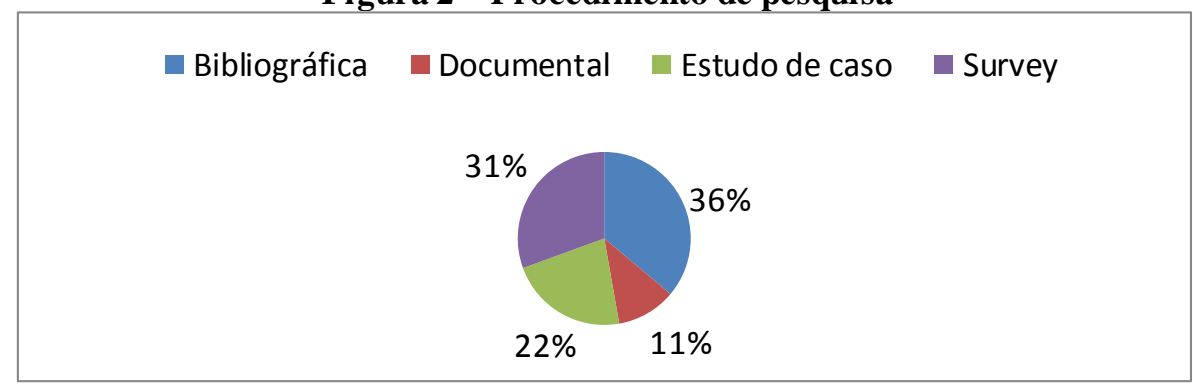

Fonte: elaborado pelos autores

Os artigos selecionados apresentam resultados de pesquisas com objetivos predominantes de natureza descritiva, uma vez que é representado por $72 \%$ das publicações, enquanto apenas $28 \%$ dos artigos possuem objetivos de pesquisa exploratória, conforme representado na figura 3:

Figura 3 - Objetivos das pesquisas

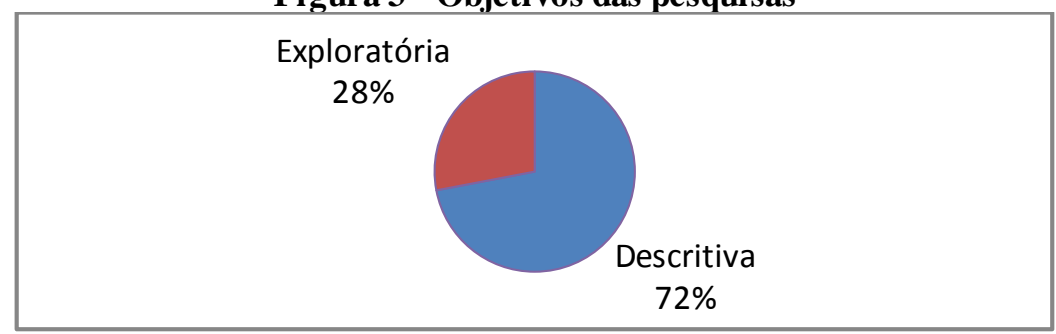

Fonte: elaborado pelos autores 
O resultado pode indicar que a maior parte dos artigos descrevem as características e comportamento das populações analisadas e alguns proporcionam um panorama geral sobre o assunto abordado.

\section{ANÁLISE DOS RESULTADOS}

Para verificar as formas de prevenção e detecção de fraudes apontadas nos artigos, realizou-se a leitura completa dos artigos que indicavam o referido assunto em seus objetivos. Dessa forma constatou-se que poucos artigos apresentam sugestões quanto a alternativas para detectar e coibir fraudes. A maioria das publicações apenas defende que cabe a administração da empresa a responsabilidade pela prevenção e detecção, além de ressaltarem que a Auditoria não pode ser responsabilizada pela ocorrência de fraudes nas demonstrações contábeis das entidades.

Nesse sentido, o ART05 indica que as mudanças de estilo de vida e as disparidades entre os bens e salários dos funcionários e ou gestores das empresas podem ser sinais de alerta para a administração das empresas (PINHEIRO; CUNHA, 2003).

No ART09, Ribeiro e Dias Filho (2007) indicam que a análise de regressão e correlação e ferramentas estatísticas podem auxiliar os auditores a evidenciar indícios de fraudes e erros, além de salientarem a importância do cumprimento aos controles internos.

Já no ART13 é destacado que o Conselho Federal de Contabilidade atribui à administração da entidade a responsabilidade pela prevenção e detecção de fraudes e erros, através da implementação e manutenção de adequados sistemas de contabilidade e controle interno. Além disso, indica que os gestores devem estabelecer diretrizes estratégicas e operacionais para estabelecer a implantação e disseminação de uma cultura de riscos e combate a fraudes (FÉLIX; RIBEIRO; TOSTES, 2008).

O ART20 indica que "um sistema de controle interno adequado funciona como uma "peneira" na detecção de erros, irregularidades e fraudes" (RITTA, 2010, p.65). O a utor afirma também que as empresas que utilizam o serviço de auditoria externa possuem melhores níveis de controle interno e por consequência menos riscos de fraudes e erros.

No mesmo sentido, o ART25 destaca a necessidade de despertar o interesse profissional de auditores e contadores para a prevenção e apuração de fraudes através da implantação de sistema de controle interno bem como da implementação de código de ética a ser seguido por toda a organização. Segundo o autor "a melhor forma de prevenção para evitar a ocorrência de fraudes é estabelecer mecanismos que coloquem essa possibilidade fora do alcance da pessoa, que direta ou indiretamente tenha interesse na sua prática" (SILVA, 2007, p.14).

O ART29, de autoria de Medeiros; Sérgio e Botelho (2004, p.4) indica diversas formas de prevenção, como se por exemplo:

- A prevenção contra fraudes deve começar a partir da contratação dos empregados, buscando saber nas empresas por onde já trabalharam, e o comportamento em que tinham. As áreas mais atingidas pelas irregularidades são os setores de compras, financeiro, de recursos humanos, como também a área de tecnologia da informação;

- Verificar se a contabilidade está correta ou se as operações estão sendo registradas;

- É ideal que as auditorias externa e interna trabalhem de forma integrada, aplicando programas de prevenção, não sendo recomendável que seja utilizada apenas a auditoria externa, pois mesmo que esta identifique um crime corporativo, dificilmente seus profissionais saberão lidar com o problema, já que lhes faltam subsídios de perícia contábil para trabalhar com caso judicial;

- Controlar sistemas de folha de pagamento, de contas a pagar e contas a receber é uma tarefa importante; Outro método de prevenção seria a instalação de 
câmeras e a infiltração de investigadores nas equipes, os chamados "funcionários espiões";

- As empresas deveriam tanto trabalhar na formação de dados estratégicos para o desenvolvimento dos seus negócios, como também se prevenir da ação criminosa de seus colaboradores ou de terceiros.

As estratégias para coibir e detectar fraudes indicadas nas publicações ressaltam a importância dos controles internos bem como a necessidade de reforçar o pensamento ético das equipes de trabalho.

Os artigos selecionados apresentam diversas abordagens sobre fraudes. Alguns artigos relacionam o papel dos controles internos com a não ocorrência de fraudes, outros indicam que o risco de fraude deve ser avaliado no planejamento da auditoria, mas que ela não é responsável pela descoberta de fraudes. Há também alguns artigos que falam sobre a necessidade de empresas atenderem as determinações SOX como forma de minimizar a ocorrência de fraudes.

Devido à amplitude dos assuntos relacionados não é possível indicar um único perfil de pesquisa. Porém pode-se constatar que o número de artigos publicados sobre fraudes contábeis é pequeno se relacionado ao número de novos casos de fraudes anunciados nos meios de comunicação.

Cabe ressaltar que a pesquisa foi realizada com todo tipo de fraude que possa estar relacionada aos processos das entidades, uma vez que a ocorrência de fraudes demonstra a existência de falhas, seja com pessoas ou com procedimentos e por consequência irão interferir nas demonstrações contábeis das empresas.

\section{CONSIDERAÇÕES FINAIS}

A Contabilidade possui como principal objetivo o fornecimento de informações úteis para a tomada de decisões. Contudo, com as constantes mudanças no sistema econômico, as empresas acabam alterando seus processos, o que, por vezes, fragiliza o sistema de controle interno, possibilitando a ocorrência de fraudes.

Nesse sentido, esta pesquisa teve por objetivo verificar como as fraudes contábeis são abordadas nos periódicos e eventos nacionais de Contabilidade no período de 2000 a 2012 . O referido objetivo foi alcançado pela quantificação e análise dos artigos selecionados.

A pesquisa realizada localizou 36 artigos publicados em periódicos e eventos nacionais de Contabilidade, no período de 2000 a 2012, que atendiam os requisitos de seleção. Verificouse que nos anos de 2000 e 2001 não houve a publicação de nenhum artigo e o ano de 2007 foi o que apresentou o maior número de publicações, ou seja, 10 artigos publicados. O periódico que apresentou o maior número de publicações foi o P18 - Revista de Contabilidade do Mestrado em Ciências Contábeis da UERJ, por essa razão o estado com maior participação de publicações sobre fraudes contábeis é o RJ, sendo que as instituições representadas com maior número de artigos publicados são a UERJ e a UFSC com 5 artigos cada.

Verificou-se também que prevalecem autores do gênero masculino e que o maior número de artigos foi elaborado por dois autores. Ainda em termos da quantidade de autores por artigo, percebe-se que apenas uma pequena parcela dos estudos analisados foi de autoria única, o que demonstra uma preocupação com a formação de redes entre os pesquisadores, tendência esta já apresentada por Costa (2010). Constatou-se que a pesquisa bibliográfica e a survey são os procedimentos de pesquisa mais utilizados nos artigos e que os objetivos de natureza descritiva dominam, uma vez que estão presentes em $72 \%$ das publicações.

A análise dos tipos de bibliografias referenciadas pelos autores dos artigos indica que os livros são as referências mais aplicadas, porém, a utilização de periódicos é crescente nas publicações atuais. Isso denota que os autores ainda consideram relevante a inclusão de livros clássicos da área, embora se saiba que os estudos publicados em periódicos são mais atualizados e representam a fronteira do conhecimento. Segundo Costa (2010), a utilização de livros como 
principal fonte de referência pode demonstrar uma postura conservadora por parte dos autores, evidenciando que os pesquisadores desse campo ainda estão divididos, além de uma possível falta de maturidade teórica da área em questão. $\mathrm{Na}$ análise dos resultados das pesquisas constatou-se que os artigos indicam como forma de prevenção a fraudes, a implantação e manutenção de controles internos adequados, além da indicação de contratar-se auditoria externa e interna.

A título de sugestão para trabalhos futuros, a ampliação da pesquisa para publicações internacionais poderia trazer uma visão mais ampla em termos de direcionamento das pesquisas sobre as fraudes contábeis e as maneiras de coibi-las, bem como sobre a efetiva utilização dos controles internos nas organizações. Além disso, sugere-se um estudo comparativo entre publicações nacionais e internacionais sobre o tema.

\section{REFERÊNCIAS}

ALBERTO, Valder Luiz Palombo. Perícia Contábil. 4. ed. São Paulo: Atlas, 2007.

ALMEIDA, Bruno José Machado de. Auditoria e sociedade: o diálogo necessário. Revista Contabilidade e Finanças. São Paulo, v.15, n.34, p.80-96, jan/abr.2004. doi: 10.1590/S151970772004000100006

ALMEIDA, José Joaquim Marques de. A auditoria legal na União Européia: enquadramento, debate actual e perspectivas futuras. Revista Contabilidade e Finanças. São Paulo, v.13, n.38, p.29-38, jan/abr.2002. doi: 10.1590/S1519-70772002000100002

ALMEIDA, Marcelo Cavalcanti. Auditoria: um curso moderno e completo. 7. ed. São Paulo: Atlas, 2010.

ANDRADE, Adélio Carlos de; SOUSA, Flávia Cristina Alves; COLAUTO, Romualdo Douglas; PINHEIRO, Laura Edith Taboada. Políticas de segurança em sistema de informação contábil: um estudo em cooperativas de crédito no estado de Minas Gerais. Revista

Contemporânea de Contabilidade. Florianópolis, ano 04, v.1, n.7, p.125-143, jan/jun.2007.

ASSING, Ildefonso; ALBERTON, Luiz; TESCH, José Marcos. O comportamento das fraudes nas empresas brasileiras. Revista da FAE, Curitiba, v.11, n. 2, p.141-152, jul/dez. 2008.

ATTIE, William. Auditoria interna. 2. ed. São Paulo: Atlas, 2009.

AVELAR, Ewerton Alex; SANTOS, Thiago de Souza; RIBEIRO, Lívia Maria de Pádua; OLIVEIRA, Clédison Carlos de. Pesquisa em Contabilidade: uma análise dos estudos empíricos publicados em periódicos nacionais entre 2000 e 2009. Revista Universo Contábil, FURB, Blumenau, v.8, n.3, p.06-23, jul/set.2012. doi:10.4270/ruc.2012319

AZEVEDO, Renato Ferreira Leitão; CORNACCHIONE JUNIOR, Edgar Bruno. Ética profissional contábil: uma análise visual da percepção pública. Revista de Educação e Pesquisa em Contabilidade. Brasília, v.6, n.1, p.19-37, jan/abr.2012.

BASTOS, Paulo Sérgio Siqueira; PEREIRA, Roberto Miguel. Fraudes eletrônicas: o que há de novo? Revista de Contabilidade do Mestrado em Ciências Contábeis da UERJ. Rio de Janeiro, v.12, n.2, p.1-10 mai/ago.2007. 
BEUREN, Ilse Maria; SCHLINDWEIN, Antônio Carlos; PASQUAL, Dino Luiz. Abordagem da Controladoria em trabalhos publicados no EnANPAD e no Congresso USP de Controladoria e Contabilidade de 2001 a 2006. Revista de Contabilidade e Finanças da USP. São Paulo, v.18, n.45, p.22-37 set/dez.2007. doi:10.1590/S1519-70772007000400003

BRASIL, CONSELHO FEDERAL DE CONTABILIDADE. Normas Brasileiras de Contabilidade. Resolução $n^{\circ}$ 1.243/ 09. Publicada no DOU de 10.12.2009. NBC TP 01Perícia Contábil. Disponível em:

<http://www.cfc.org.br/sisweb/sre/detalhes_sre.aspx?codigo=2009/001243>. Acesso em: 27 mai. 2012.

CONSELHO FEDERAL DE CONTABILIDADE. Normas Brasileiras de Contabilidade. Resolução no 1.207/ 09. Publicada no DOU de 27.11.2009. NBC TA 240 Responsabilidade do Auditor em Relação a Fraude, no Contexto da Auditoria de Demonstrações Contábeis. Disponível em: <http://www.cfc.org.br/sisweb/sre/detalhes_sre.aspx?Codigo=2009/001207>. Acesso em: 27 mai. 2012.

CARDOSO, Ricardo Lopes; MENDONÇA NETO, Octávio Ribeiro de; RICCIO, Edson Luiz; SAKATA, Marici Cristine Gramacho. Pesquisa científica em contabilidade entre 1990 e 2003. Revista de Administração de Empresas - RAE, v.45, n.2, p.35-45, abr/jun.2005. http://dx.doi.org/10.1590/S0034-75902005000200004

CARDOSO, Ricardo Lopes; PEREIRA, Carlos Alberto; GUERREIRO, Reinaldo. Perfil das Pesquisas em Contabilidade de Custos Apresentadas no EnANPAD no Período de 1998 a 2003. Revista de Administração Contemporânea, v.11, n.3, p.177-198, Jul/Set.2007. doi: 10.1590/S1415-65552007000300009

CARDOZO, Julio Sérgio de Souza. Governança corporativa: solução, paliativo ou modismo. Revista de Contabilidade do Mestrado em Ciências Contábeis da UERJ. Rio de Janeiro, v.10, n.2, p.41-50, 2005.

CERVO, Amado Luiz; BERVIAN, Pedro Alcino. Metodologia Científica. 5. ed. São Paulo: Prentice Hall, 2002.

COELHO, Cláudio Ulysses Ferreira; LINS, Luiz dos Santos. Teoria da Contabilidade: abordagem contextual, histórica e gerencial. São Paulo: Atlas, 2010.

COSTA, Flaviano. A produção do saber nos campos de controladoria e contabilidade gerencial: uma análise da produção científica inspirada na arqueologia foucaultiana Dissertação (Mestrado) - Universidade Federal do Paraná. Programa de Pós-Graduação em Contabilidade. Curitiba, 2010.

COUTINHO E SILVA, Adolfo Henrique; SANCOVSCHI, Moacir; CARDOZO, Julio Sérgio de Souza; CONDE, Robson Augusto Dainez. Teoria dos escândalos corporativos: uma análise comparativa de casos brasileiros e norteamericanos. Revista de Contabilidade do Mestrado em Ciências Contábeis da UERJ. Rio de Janeiro, v.17, n.1, p.92-108, jan/abr.2012.

CREPALDI, Silvio Aparecido. Auditoria Contábil: teoria e prática. 6. ed. São Paulo: Atlas, 2010. 
CUNHA, Paulo Roberto; RAUSCH, Rita Buzzi; CUNHA, Jacqueline Veneroso Alves da. Contabilidade internacional: uma análise metodológica e técnica das pesquisas publicadas no Congresso USP de Controladoria e Contabilidade e na Revista de Contabilidade \& Finanças da USP. Contabilidade, Gestão e Governança, v. 13, n. 3, p. 116-131, 2010.

DANTAS, José Alves; RODRIGUES, Fernanda Fernandes; MARCELINO, Gileno Fernandes; LUSTOSA, Paulo Roberto Barbosa. Custo-benefício do controle: proposta de um método para a avaliação com base no COSO. Contabilidade, Gestão e Governança. Brasília, v.13, n.2, p.3-19, mai/ago.2010.

DINIZ, Josedilton Alves; CORRAR, Luiz João; SLOMSKI, Valmor. Análise digital: uma abordagem cognitiva na detecção de não conformidade em prestações municipais. In: CONGRESSO USP DE CONTROLADORIA E CONTABILIDADE, 10, 2010, São Paulo. Anais.... São Paulo: USP, 2010. Disponível em: <http://www.congressousp.fipecafi.org/artigos102010/474.pdf>. Acesso em: 21 ago. 2012.

ECKERT, Alex. Teoria da Contabilidade para o Exame de Suficiência do CFC. 2. ed. São Paulo: Edipro, 2013.

FAJARDO, Bernardo de Abreu Guelber; CARDOSO, Ricardo Lopes. Viagem ao centro da denúncia: explorando as "camadas" que influenciam as denúncias de fraudes nas organizações, na perspectiva dos contabilistas. In: CONGRESSO ANPCONT, 6, 2012, Florianópolis. Anais eletrônicos... Florianópolis: FURB, 2012. Disponível em: <https://www.furb.br/especiais/download/803031-906307/CCG\%20224.pdf>. Acesso em: 16 set.2012.

FAJARDO, Bernardo de Abreu Guelber; LEÃO, Guilherme Abib. O efeito priming na avaliação de ações antiéticas: um estudo experimental. Revista de Administração Contemporânea. v. 18, n. 1, 2014. doi: 10.1590/S1415-65552014000100005

FÉLIX, Cláudia Lima; RIBEIRO, Heliton José; TOSTES, Fernando P. Uma contribuição à análise de fatores que influenciam o equilíbrio do sistema previdenciário. Pensar Contábil, v.10, n.39, p.23-28, jan/mar.2008.

FERNANDES, Francisco Carlos; KROENRE, Adriana; SÖTHE, Ari. Uma visão atual do processo de controle e gerenciamento de riscos operacionais nos maiores bancos brasileiros. Revista de Informação Contábil, v.4, n.2, p.1-20, abr/jun.2010.

FERREIRA, Aghata Frade. Uma análise das fraudes contábeis através da leitura de revistas internacionais de contabilidade. 2010. Monografia (Graduação) - Universidade Federal de Santa Catarina, 2010.

FONSECA, Nelson Ferreira; BRESSAN, Aureliano Angel; IQUIAPAZA, Robert Aldo; GUERRA, João Paulo. Análise do Desempenho Recente de Fundos de Investimento no Brasil. Contabilidade Vista e Revista, v.18, n.1, p.95-116, 2007.

FRANCO, Hilário. Contabilidade Geral. 23 ed. São Paulo: Atlas, 1996.

FRANCO, Hilário; MARRA, Ernesto. Auditoria Contábil. 2 ed. São Paulo: Atlas, 1992. 
FREITAS, Andréia Ciryno de; DIEHL, Carlos Alberto; MACAGNAN, Clea Beatriz. A percepção sobre ética de estudantes de curso de graduação em Ciências Contábeis. Revista de Educação e Pesquisa em Contabilidade. Brasília, v.5, n.1, p.21-49, jan/abr.2011.

FUJI, Alessandra Hirano; CARVALHO, Luiz Nelson Guedes de. Earnings Management no contexto bancário brasileiro. In: CONGRESSO USP DE CONTROLADORIA E CONTABILIDADE, 5., 2005, São Paulo. Anais eletrônicos.... São Paulo: USP, 2005. Disponível em: < http://www.congressousp.fipecafi.org/artigos52005/7.pdf>. Acesso em: 21 ago.2012.

FURASTÉ, Pedro Augusto. Normas Técnicas para o Trabalho Científico: Elaboração e Formatação. Explicitação das Normas da ABNT. 14. ed. Porto Alegre: Gráfica e Editora Brasul Ltda, 2006.

GELATTI, Cristiane Braida; MENEGHETTI, Daniela. Análise da adequação das empresas brasileiras à Lei Sarbanes-Oxley. Revista Brasileira de Contabilidade, n. 186, p.69-83, nov/dez. 2010.

GERON, Cecília Moraes Santostaso; FINATELLI, João Ricardo; FARIA, Ana Cristina de; ROMEIRO, Maria do Carmos. SPED - Sistema Público de Escrituração Digital: percepção dos contribuintes em relação aos impactos de sua adoção. Revista de Educação e Pesquisa em Contabilidade. Brasília, v.5, n.2, p.44-67, mai/ago.2011.

GIL, Antonio Carlos. Métodos e técnicas de pesquisa social. 5. ed. São Paulo: Atlas, 1999.

GRECO, Alvísio Lahorgue; AREND, Lauro; GARTNER, Gunter. Contabilidade: teoria e prática básicas. 2. ed. ver. e atual. São Paulo: Saraiva, 2009.

HASTINGS, David F. Bases da contabilidade: uma discussão introdutória. São Paulo, Saraiva, 2007.

HENDRIKSEN, Eldon S.; VAN BREDA, Michael F; Tradução de Antonio Zoratto Sanvicente. Teoria da Contabilidade. São Paulo: Atlas, 1999.

IUDÍCIBUS, Sérgio de. Teoria da Contabilidade. 5. ed. São Paulo: Atlas, 1997.

IUDÍCIBUS, Sérgio de; MARION, José Carlos; PEREIRA, Elias. Dicionário de termos em contabilidade. 2. ed. São Paulo: Atlas, 2003.

JUND, Sérgio. Auditoria: conceitos, normas, técnicas e procedimentos: Teoria e 950 questões. 9. ed. Rio de Janeiro: Elsevier, 2007

JUVENAL, Denise Silva Ferreira;CAMPAGNAC, Luiz Antonio. A evidenciação da informação contábil com relação à tributação no comércio eletrônico: um estudo de caso .

Pensar Contábil, v.9, n.36, p.29-34, abr/jun.2007.

KÖCHE, José Carlos. Fundamentos de metodologia científica: teoria da ciência e iniciação à pesquisa. 27. Ed. Petrópolis, RJ: Vozes, 2010.

KRANACHER, M. J., RILEY, R.,; WELLS, J. T. Forensic accounting and fraud examination. Hoboken, NJ: Ed. John Wiley and Sons Ltda. 2010. 
FRAUDES CONTÁBEIS: CARACTERIZAÇÃO E ANÁLISE DAS PUBLICAÇÕES EM PERIÓDICOS E EVENTOS NACIONAIS DE CONTABILIDADE

LEITE FILHO, G. A.; SIQUEIRA, R. L. Revista Contabilidade e Finanças USP: Uma Análise Bibliométrica de 1999 a 2006. RIC - Revista de Informação Contábil, v. 1, n. 2, p.02-119, 2007.

LOPES, Alexsandro Broedel e MARTINS, Eliseu. Teoria da contabilidade: uma nova abordagem. São Paulo: Atlas, 2007.

LUCIANI, Josiane Carla Jamoski; CARDOSO, Nerian José; BEUREN, Ilse Maria. Inserção da Controladoria em artigos de periódicos nacionais classificados no Sistema Qualis da CAPES. Contabilidade Vista e Revista, v. 18, n. 1, p. 11-26, 2007.

LUNKES, Rogério João; ROSA, Fabrícia Silva da. O uso do controle interno na gestão das operações: um estudo de caso em empresa hoteleira. Revista Catarinense da Ciência Contábil. Florianópolis, v.5, n.13, p.43-58, dez.2005/ mar.2006.

MARION, José Carlos. Contabilidade básica. 9. ed. São Paulo: Atlas, 2008.

MATSUMOTO, Alberto Shigueru; PARREIRA, Eneias Medeiros. Gerenciamento de resultados contábeis: causas e consequências. In: CONGRESSO USP DE CONTROLADORIA E CONTABILIDADE, 7, 2007, São Paulo. Anais eletrônicos... São Paulo: USP, 2007. Disponível em:

<http://www.congressousp.fipecafi.org/artigos72007/27.pdf>. Acesso em: 25 ago. 2012.

MEDEIROS, Andressa Kely de; SÉRGIO, Lucicleia de Moura; BOTELHO, Ducineli Régis. A importância da Auditoria e Perícia para o combate a fraudes e erros na Contabilidade das empresas. In: CONGRESSO USP DE CONTROLADORIA E CONTABILIDADE, 4, 2004, São Paulo. Anais eletrônicos... São Paulo: USP, 2004. Disponível em: <http://www.congressousp.fipecafi.org/artigos12004/380.pdf>. Acesso em: 23 mar. 2012.

MENDONÇA, Mark Miranda de; ANTUNES, Gustavo Amorim; AZEVEDO, Filipe Bressanelli; COSTA, Fábio Moraes da. O impacto da lei Sarbanes-Oxley (SOX) no conservadorismo contábil das empresas brasileiras que emitiram ADR antes de 2002: uma investigação utilizando dados em painel. In: CONGRESSO USP DE CONTROLADORIA E CONTABILIDADE, 8., 2008, São Paulo. Anais eletrônicos.... São Paulo: USP, 2008. Disponível em: < http://www.congressousp.fipecafi.org/artigos82008/452.pdf>. Acesso em: 21 ago.2012.

MENEGUSSI, Elires Marinho de Melo; IANESKO, José Augusto. A importância da auditoria contábil na prevenção e combate aos erros e às fraudes nas organizações. Revista Eletrônica Lato Sensu - Unicentro, 6. ed, 2008. Disponível em: <web03.unicentro.br/especializacao/Revista.../1-Ed6_CS-ImpAu.pdf>. Acesso em: 30 mar. 2012.

MURCIA, Fernando Dal-Ri; BORBA, José Alonso. Um estudo das fraudes contábeis sob duas óticas: jornais econômicos versus periódicos acadêmicos no período de 2001-2004.

Revista de Contabilidade do Mestrado em Ciências Contábeis da UERJ. Rio de Janeiro, v.10, n.2, p.99-114, 2005.

MURCIA, Fernando Dal-Ri; BORBA, José Alonso; SCHIEHLL, Eduardo. Relevância dos red flags na avaliação do risco de fraudes nas demonstrações contábeis: a percepção de auditores independentes brasileiros. In: CONGRESSO USP DE CONTROLADORIA E 
CONTABILIDADE, 7., 2007, São Paulo. Anais eletrônicos.... São Paulo: USP, 2007. Disponível em: < http://www.congressousp.fipecafi.org/artigos72007/333.pdf>. Acesso em: 21 ago.2012.

OLIVEIRA, Alexandre Queiroz de; SANTOS, Neusa Maria Bastos Fernandes dos. Rodízio de firmas de auditoria: a experiência brasileira e as conclusões do mercado. Revista Contabilidade e Finanças. São Paulo, v.18, n.45, p.91-100, set/dez.2007. doi:10.1590/S1519-70772007000400009

OLIVEIRA, Josiele Conceição Roldão de; ZAPPALA, Antonio Carlos Guedes; BISPO, Oscar Neto de Almeida; SOARES, Marcos Valerio Martins. O papel do controle interno na prevenção de erros e fraudes: um estudo de caso em cooperativa de crédito de Minas Gerais. In: CONGRESSO USP DE CONTROLADORIA E CONTABILIDADE, 11., 2011, São Paulo. Anais eletrônicos.... São Paulo: USP, 2011. Disponível em: <http://www.congressousp.fipecafi.org/artigos112011/470.pdf>. Acesso em: 21 ago.2012.

OLIVEIRA, Marcelle Colares. Análise dos periódicos brasileiros de Contabilidade. Revista Contabilidade e Finanças. São Paulo, n.29, p 68-86, maio/ago.2002. doi:10.1590/S151970772002000200005

PELEIAS, Ivam Ricardo; SEGRETI, João Bosco; COSTA, Catarina de Araújo. Comitê de auditoria ou órgãos equivalentes no contexto da Lei Sarbaes-Oxley: estudo da percepção dos gestores de empresas brasileiras emitentes de American Depositary Receipts - ADRs.

Contabilidade Vista \& Revista. Belo Horizonte, v.20, n.1, p.41-65, jan/mar.2009.

PEREIRA, Anísio Candido; NASCIMENTO, Wesleey, Souza do. Um estudo sobre a atuação da auditoria interna na detecção de fraudes nas empresas do setor privado no estado de São Paulo. Revista Brasileira de Gestão de Negócios. São Paulo, v.7, n.19, p. 46-56, 2005. Doi: 10.7819/rbgn.v7i19.49

PEREIRA, Antonio Nunes. Controles internos empresariais e gestão: visões e importância uma abordagem exploratória. Contabilidade Vista \& Revista. Belo Horizonte, v.15, n.3, p.27-44, dez.2004.

PINHEIRO, Geraldo José; CUNHA, Luís Roberto Silva. A importância da auditoria na detecção de fraudes. Contabilidade Vista \& Revista. Belo Horizonte, v.14, n.1, p.31-48, abr.2003.

PINHO, Ruth Carvalho de Santana. Fundamentos de auditoria: auditoria contábil: outras aplicações de auditoria. São Paulo: Atlas, 2007.

RIBEIRO, Joselito de Macedo; DIAS FILHO, José Maria. Aplicação de métodos quantitativos em auditoria: propostas para otimizar procedimentos e reduzir riscos. Revista de Contabilidade e Organizações, v.1, n.1, p.43-59, set/dez.2007.

RICHARDSON, Roberto Jarry. Pesquisa social: métodos e técnicas. 3. ed. São Paulo: Atlas, 1999.

RITTA, Cleyton de Oliveira. Análise comparativa do controle interno no contas a receber e a pagar nas empresas Beta Ltda e Alfa Ltda. Revista Catarinense da Ciência Contábil. Florianópolis, v.9, n.26, p.63-78, abr/jun.2010. 
FRAUDES CONTÁBEIS: CARACTERIZAÇÃO E ANÁLISE DAS PUBLICAÇÕES EM PERIÓDICOS E EVENTOS NACIONAIS DE CONTABILIDADE

SÁ, Antônio Lopes de. Fundamentos da contabilidade geral. 3. ed. $2^{\mathrm{a}}$ reimpr. Curitiba:Juruá, 2010.

SANTOS, Josenildo dos; RIBEIRO FILHO, José Francisco; LAGIOIA, Umbelina; ALVES FILHO, Bartolomeu Figueiredo; ARAÚJO, Ivson José Caldas de. Aplicações da lei de Newcomb-Benford na auditoria tributária do imposto sobre serviços de qualquer natureza (ISS). Revista Contabilidade e Finanças. São Paulo, v.20, n.49, p.79-94, jan/abr.2009. doi: 10.1590/S1519-70772009000100006

SANTOS, Luciana de Almeida Araújo; LEMES, Sirlei. A Lei Sarbanes-Oxley: uma tentativa de recuperar a credibilidade do mercado de capitais norte-americano. In: CONGRESSO USP DE CONTROLADORIA E CONTABILIDADE, 4., 2004, São Paulo. Anais eletrônicos.... São Paulo: USP, 2004. Disponível em:

<http://www.congressousp.fipecafi.org/artigos12004/299.pdf>. Acesso em: 21 ago.2012.

SANTOS, Nivaldo João dos. Perspectivas da profissão Contábil. Revista Catarinense da Ciência Contábil. Florianópolis, v.1, n.3, p.7-11, ago.2002/ nov.2002.

SELVARAJAN, R.; CLONINGER, P. A. The importance of accurate performance appraisals for creating ethical organizations. The Journal of Applied Business Research, v. 4, n. 3, p. 39-44, 2008.

SILVA, Letícia Medeiros; NASCIMENTO, Auster Moreira; OTT, Ernani. A influência da lei Sarbanes-Oxley e do Código Civil Brasileiro nos controles internos de empresas localizadas no Brasil. In: CONGRESSO USP DE CONTROLADORIA E CONTABILIDADE, 7., 2007, São Paulo. Anais eletrônicos.... São Paulo: USP, 2007.

SILVA, Lino Martins da. Atuação dos contadores e auditores na descoberta e na apuração de fraudes: uma reflexão. Revista de Contabilidade do Mestrado em Ciências Contábeis da UERJ. Rio de Janeiro, v.12, n.1, p.1-18 jan/abr.2007.

SOUZA, Audrey Jones de; CARDOSO, Ricardo Lopes. Impactos da adoção dos IFRSs na perícia criminal. In: CONGRESSO USP DE CONTROLADORIA E CONTABILIDADE, 12., 2012, São Paulo. Anais eletrônicos.... São Paulo: USP, 2012. Disponível em: <http://www.congressousp.fipecafi.org/artigos122012/526.pdf>. Acesso em: 21 ago.2012.

SOUZA, Flávia Cruz de; BORBA, José Alonso. Governança corporativa e remuneração de executivos: uma revisão dos artigos publicados no exterior. Contabilidade Vista \& Revista. Belo Horizonte, v.18, n.2, p.35-48, abr/jun.2007.

SOUZA, José Carlos de; SCARPIN, Jorge Eduardo. Fraudes Contábeis: as respostas da contabilidade nos Estados Unidos e na Europa. In: SIMPÓSIO DE EXCELÊNCIA EM GESTÃO E TECNOLOGIA. 3., 2006, Rio de Janeiro. Anais eletrônicos... Rio de Janeiro: AEDB, 2006. Disponível em: < http://www.aedb.br/seget/artigos06/493_Fraudes\%20\%20SEGET.pdf>. Acesso em: 27 mai. 2012.

UNIVERSIDADE FEDERAL DO PARANÁ. Normas para apresentação de documentos científicos. Sistema de Bibliotecas. Periódicos e artigos de periódicos. Curitiba: UFPR, 2000.

ZANNA, Remo Dalla. Prática de perícia contábil. 2. ed. São Paulo: IOB Thomson, 2007. 